Fecha de recepción: marzo 2009 Fecha de aceptación: abril 2009 Versión final: noviembre 2009

\section{El paisaje como referente de diseño}

Jimena Martignoni *

\begin{abstract}
Resumen: Muchas de las más emblemáticas y significativas disciplinas de diseño actuales, tanto como otras cuyo centro es el hombre -sus necesidades y sus comportamientos- poseen un lazo profundamente necesario y definido con el paisaje. Se alimentan y se inspiran en él, se refieren a él y son referentes del mismo, se originan en él y al mismo tiempo lo conforman y lo transforman.

¿Cuál es ese lazo y cómo se define exactamente? ¿A qué nos remiten las duplas paisaje-arquitectura, paisaje-ciudad, paisaje-cuerpo, paisaje-teatro, paisaje-tiempo y paisaje-rito?

Este texto-disparador busca inspirar a cada uno de los autores para que, con sus ideas, conceptos y ejemplos, dejen al descubierto algo más de la esencia de aquel maravilloso lazo.
\end{abstract}

Palabras claves: Paisaje-arquitectura - indumentaria-cuerpo - escenografía-teatro - ciudad-mobiliario urbano - historia-tiempo - antropología-rito

[Resúmenes en inglés y portugués y currículum en las páginas 19-20]

El objetivo de este ensayo es comprender, reconocer y valorar el paisaje y el diseño y la intervención en el mismo -con fines funcionales o con unos exclusivamente formales- como referencia visual y cultural primaria para diversas disciplinas actuales de diseño y para otras tantas relacionadas directamente con la dinámica cultural del hombre.

La manera a través de la cual se propone la comprobación y profundización de esta idea es la presentación de perspectivas, posiciones, experiencias, ejemplos proyectuales, situaciones reales, análisis, utopías, críticas e incluso cuestionamientos, todo lo cual pone de manifiesto y explora el objetivo propuesto.

Para esto se invitaron seis autores que representan seis especialidades diferentes y todos los cuales poseen una sensibilidad y un interés especial en el tema que convoca. Cada uno de ellos debió, en base a un escrito disparador que se presenta a continuación, elaborar un texto que reflejara el rol, el significado y la influencia que el paisaje posee visual y culturalmente dentro del marco de cada una de dichas especialidades y desde sus perspectivas específicas.

En el texto-disparador se plantean: primero, una profundización en el significado del concepto de diseño, intentando a través de un proceso de simplificación y búsqueda de su esencia, establecer lazos con el concepto de paisaje; segundo, una serie de analogías con el paisaje, desde las seis especialidades de los autores: paisaje y arquitectura; paisaje, ciudad y mobiliario urbano; paisaje, cuerpo y vestido; paisaje, escenografía y teatro; paisaje y antropología; paisaje, historia y marcas en el tiempo. 


\section{¿Qué es diseño y qué es paisaje?}

Pensar en el paisaje como referente de diseño comienza a implicar tantas imágenes visuales, tantas experiencias sensoriales y tantos conceptos filosóficos y antropológicos que pareciera imposible encontrar un lugar a través del cual decantar toda esa información y decir algo coherente sin caer en una repetición de ideas y pensamientos ya antes volcados una y mil veces o, en caso contrario, sin temor a añadir más imágenes y conceptos que no aclaren la idea inicial.

Esto se debe, justamente, a que el paisaje remite (porque lo es) a una sucesión de imágenes y conceptos que ya están predeterminados en nuestra conciencia de habitantes de lugares diversos. Intentar no andar por caminos que se bifurcan cuando se trata de definir al paisaje es casi un imposible. La tarea se complica, aun más, cuando entra también, con un rol primordial, la noción de diseño: ¿Cuántas otras infinitas imágenes comienzan a desdoblarse a partir de querer descifrar y precisar la acción de diseñar?

La posibilidad de llegar a unos conceptos claros, concisos y, preferentemente, nuevos, debe nutrirse del cruce y proceso de tanta información como exista con respecto al tema; sin embargo, un buen punto de partida es siempre la "simplificación" de algunos significados que luego pueden ir sumándose a otros y, a manera de constante in crescendo, cumplir el objetivo inicial. En un tiempo en el cual sobran las definiciones, las referencias y las manifestaciones en general, se hace indispensable encontrar los significados reales y profundos de aquellas cosas e ideas a las que algunos remitimos cotidianamente y, quizás, por eso mismo van perdiendo sentido y peso. Significados despojados de toda pretensión que no lleve a otra cosa que a una mayor comprensión del universo en que nos movemos.

Esta "vuelta a las raíces" puede iniciarse, en este caso, a través de una simple búsqueda de diccionario, la cual puede convertirse en el disparador de un proceso fascinante de superposición y retroalimentación de conceptos. Según la Real Academia Española, referente primero de nuestra lengua, las acepciones básicas de "diseño" son las siguientes:

1. Traza o delineación de un edificio o de una figura.

2. Proyecto, plan.

3. Concepción original de un objeto u obra destinados a la producción en serie.

4. Forma de cada uno de estos objetos.

5. Descripción o bosquejo verbal de algo.

6. Disposición de manchas, colores o dibujos que caracterizan exteriormente a diversos animales y plantas.

Traza, proyecto, concepción, forma, descripción, bosquejo verbal y disposición son las palabras claves. Una segunda búsqueda, del significado de cada una de ellas, deja como resultado las siguientes definiciones:

- Traza: huella, vestigio.

- Proyecto: primer esquema o plan de cualquier trabajo que se hace a veces como prueba antes de darle la forma definitiva.

- Concepción, concebir: formar idea, hacer concepto de algo.

- Forma: Configuración externa de algo.

- Descripción, describir: Delinear, dibujar, figurar algo, representándolo de modo que dé cabal idea de ello.

- Bosquejo (verbal): Idea vaga de algo. 
- Disposición, disponer: Colocar, poner algo en orden y situación conveniente.

Cada palabra abre un nuevo camino con nuevas bifurcaciones y la complejidad de integración de conceptos se hace aún mayor; sin embargo, con este proceso comienzan a vislumbrarse de a poco ciertos matices compartidos, ciertas referencias y ciertas acciones referidas comunes, todo lo cual permite una mejor identificación de un concepto catalizador. El marco: la creación.

Trazar una figura, concebir una idea, poner en orden, son todas acciones propias del diseño; queda claro, entonces, que el acto para el cual el paisaje es o puede ser un referente es uno que se identifica plenamente con la posibilidad de crear, lo cual se traduce como fundar y producir.

Podría comenzar a explicarse el paisaje como "referente de trazados, concepciones, formas y configuraciones". ¿Pero acaso no coinciden estas acciones exactamente con la idea de lo que es un paisaje?

Las acepciones del mismo, en la Real Academia Española, son:

1. Extensión de terreno que se ve desde un sitio.

2. Extensión de terreno considerada en su aspecto artístico.

3. Pintura o dibujo que representa cierta extensión de terreno.

Más allá de las evidentes connotaciones geográficas y escalares que vienen con estas definiciones, aparecen dos conceptos que definen de manera particular al paisaje: la mirada y la representación artística. Ya ampliamente estudiado, el tema de la presencia del hombre como condición fundamental de la existencia de un "paisaje" nos lleva a entender el mismo como una construcción cultural; como tal, el paisaje es también entendido como diseño.

Una de las acepciones, anteriormente mencionadas, de este último dice "Disposición de manchas, colores o dibujos que caracterizan exteriormente a diversos animales y plantas". ¿ No podría esta imagen, profundamente visual, ser caratulada como un paisaje? ${ }_{i} \mathrm{O}$, al menos, en nuestra mente, materializarse como tal?

Todas estas superposiciones de palabras, conceptos e imágenes no hacen más que ir definiendo, aunque de manera compleja, el carácter de reciprocidad entre paisaje y diseño. Todas las acciones (proyectar, disponer, delinear) e ideas (trazo, huella, forma, configuración) que modelan y establecen al diseño, modelan y establecen también al paisaje; podría ser, no obstante, que algunas acciones de carácter más específico no coincidieran con el mismo. Por ejemplo, al hablar de producción en serie o de bosquejo verbal podemos remitir al diseño, industrial en el primer caso o relacionado con la descripción oral de un objeto en el último, pero sería imposible remitir fácilmente al paisaje. Por otro lado, no todas las acciones e ideas que modelan y establecen al paisaje lo hacen también con el diseño; un diseño cualquiera podría ser sin lugar a dudas una "pintura o dibujo", podría hasta intentar comprenderse como una "extensión" de alguna cosa, una configuración que ocupa un lugar en el espacio y puede apreciarse desde la mirada, pero nunca podría explicarse al diseño como una "extensión de terreno".

El concepto de la tierra aparece como exclusivamente propio del paisaje; con ella, se incorporan la naturaleza como marco, sus ciclos y sus atributos. Estos últimos aparecen, además, como representaciones ya formuladas y reformuladas en la memoria del hombre, el cual mira, vive y construye el paisaje. La relación, una vez más, no es linear.

El paisaje podría definirse entonces como la configuración que, con elementos y relaciones propias de la naturaleza, el hombre hace de un sitio en particular y la cual se eleva en el presente, a través de maneras diversas, como posible referente formal, funcional e histórico para cualquier disciplina de diseño. 
Esta configuración responde, casi de manera sistemática, a las necesidades del hombre. Las más básicas, mayormente representadas en las modificaciones y modelados del paisaje que realizaron las civilizaciones antiguas y de las cuales algunas aun se preservan, pueden graficarse por ejemplo con los asentamientos agrícolas en Cuzco, los bordes del Nilo en Egipto o las terrazas arroceras de Filipinas; las necesidades más superficiales, que terminan respondiendo realmente a deseos (desmesurados) del hombre, podrían representarse con los actuales sistemas "seudourbanos" que lindan con lo surrealista como por ejemplo el complejo hotelero Burj al-Arab en los Emiratos Árabes.

Las necesidades básicas del hombre siguen siendo objeto de la modelación del territorio, pero la complejidad de hoy es tal que el proceso involucra una escala mucho mayor de componentes, relaciones y resultados.

Sea cual fuera el modelado e intervención de un paisaje existente, sus resultados visuales son material de inspiración para diversas áreas del diseño. De esta manera, comienzan también a poder identificarse directamente aquellas necesidades del hombre con algunas de las que hoy se constituyen como esas áreas. Estableciendo una simple relación de correspondencia entre unas y otras, podemos obtener las siguientes analogías:

- A la necesidad de abrigo para el cuerpo y de identificación personal y de grupo se corresponde el diseño de indumentaria.

- A la necesidad de prácticas rituales, recreación y comunicación se corresponde el diseño teatral y la escenografía.

- A la necesidad de refugio, habitación y trascendencia se corresponde la arquitectura.

- A la necesidad de espacios de encuentro, publicidad e interacción social se corresponde el diseño urbano y su mobiliario.

Con una perspectiva aun más amplia, algunos de los procesos que derivan en la modelación del paisaje pueden también identificarse como disparadores conceptuales para el análisis y el desarrollo de otras disciplinas de estudio del hombre:

La Antropología, por ejemplo, como una disciplina integradora en la cual se conjugan los elementos naturales, las relaciones sociales y, sobre todo, las huellas que el hombre va dejando en el territorio y las condiciones que este último le impone. Por otro lado, la Historia, como una herramienta que permite encontrar, en el pasado y en el camino que se va haciendo hasta el presente, modalidades, ritos, mitos, procesos y cambios que describen el pasaje del hombre por esta tierra. El paso del tiempo, aunque a veces incomprensible, es otro elemento que define la conformación de paisajes.

La posibilidad, entonces, de encontrar analogías visuales y conceptuales entre cada una de las disciplinas mencionadas, seleccionadas particularmente para este trabajo, y el paisaje es no solamente real sino absolutamente atractiva, necesaria y reveladora.

\section{Analogías (poéticas)}

\section{Vestido(s) [o Cuerpo(s)]}

"Todo lo rodeaba el milagro vegetal del paisaje de tu cuerpo. Sobre tu forma, a mi tacto respondieron las pestañas de las flores, los rumores de los ríos. Todas las frutas había en el jugo de tus labios..." (Frida Kahlo, del Diario de Frida Kahlo, un autorretrato íntimo) 
En el sufrimiento desesperado de su propio cuerpo, Frida Kahlo encontró la inspiración para lo que es una de las obras pictóricas del siglo XX más intensas, significativas y provocativas visual y psicológicamente. Víctima de un terrible accidente que le quitó movilidad, libertad y la posibilidad de una vida larga, esta artista mexicana logró canalizar el dolor físico, cuando posible, a través de la creación. El paisaje de su obra es el paisaje de su "cuerpo roto", como ella solía definirlo.

El dolor a flor de piel, explícito, o el paisaje de sus formas visibles: su rostro, sus piernas, su cuerpo entero, en partes, desdoblado o duplicado; el dolor de la lucha interna, íntima, o el paisaje de sus formas no-visibles: la contraposición del sol y la luna, el imaginario azteca, las flores, los colores, sus ojos negros y su mirada fija.

Sin embargo, no es solo el paisaje corporal el que la describe, sino justamente el de las formas que lo cubren. En la introducción a la publicación del diario de Frida Kahlo, el autor mexicano Carlos Fuentes dice, al detallar la primera vez que la vio, apareciendo en escena en un concierto en el Palacio de Bellas Artes de México DF: "Fue la entrada de una diosa Azteca..." Los collares, los anillos, las blusas floreadas y las largas faldas eran su marca personal, la marca que había elegido basada en la cultura que alimentaba su vida y su obra, pero además, como signo de plenitud, en contraposición al dolor que le había sido signado por el destino.

"El vestido era también una forma de humor" -continua Carlos Fuentes- "un gran disfraz, una forma de autoerotismo teatral, pero al mismo tiempo una llamada a imaginar el sufrimiento, al cuerpo desnudo debajo y a descubrir sus secretos". El paisaje de su indumentaria era para Frida otra manera de expresarse, o de refugiarse, de redimir su dolor y de atraer el no-dolor.

"Las ropas de Frida Kahlo eran, no obstante, más que una segunda piel. Según ella misma lo dijo: Eran una manera de vestirse para el paraíso, de preparase para la muerte".

El paisaje de México, que la acompañó durante toda su vida, tanto el de su naturaleza exuberante como el de la historia de su pueblo y las culturas precolombinas que lo originaron, fueron la inspiración para lo que sería la representación de Frida para los demás. No se entiende ni se remite a Frida Kahlo sin sus pinturas expresionistas, simbólicas y auto-referenciales, como tampoco se la visualiza sin esa imagen que ella bosquejó y pintó de sí misma con prendas coloridas, joyas artesanales, chales largos y flores tropicales.

El cuerpo como habitación del alma: las expresiones de la mirada, la sonrisa, el andar; el cuerpo como reflejo del paisaje que nos conforma: el color y la contextura de la piel; el vestido como el paisaje construido del cuerpo: las formas conocidas de la naturaleza cercana y la historia, aplicadas en la indumentaria personal.

\section{Escenografía(s)}

El arte posee la capacidad de detenernos, de ralentizar nuestro ritmo y de restituir el valor del tiempo a la lentitud de la contemplación. El arte despierta de nuevo nuestro interés por todo lo que nos rodea, suprime las reglas y reescribe el espacio en que vivimos. Las artscapes restablecen el desorden en que vivimos. (Luca Galofaro, Artscapes: el arte como aproximación al paisaje contemporáneo)

El paisaje es, substancialmente, cambiante. Sin embargo, hay algunos paisajes especialmente efímeros; son paisajes-escenografías que se instalan por un tiempo, modifican visual y conceptualmente, y 
luego se retiran, sin dejar pasar el momento de gloria. También, por supuesto, hay escenografías teatrales, que utilizan el paisaje como espacios contenedores; pero, una vez más: ¿cuál origina a cuál? En su última obra, Christo y Jeanne-Claude potenciaron y expusieron el valor altamente público del sitio más visitado, más iconográfico y más conocido de una de las ciudades más publicas del planeta: instalaron, durante dos semanas, una serie de estructuras a manera de "puertas" a lo largo de todos los senderos del Central Park, en New York. Con esto devolvieron la atención de miles de locales y visitantes hacia un lugar que, aunque omnisciente y testigo cotidiano de sus vidas, puede llegar a perder su sentido más profundo; o, entendiéndolo desde una perspectiva contraria, demostraron como un paisaje efímero, enmarcado en un paisaje profundamente establecido, física y culturalmente, puede poner en valor todos aquellos elementos y comportamientos que van perdiendo significado con el tiempo. La posibilidad de la acción revela el espacio, lo redefine y mediatiza y, por otro lado, la exposición visual del mismo, su "artealización" y puesta en escena le permiten volver a expresarse en toda su plenitud.

The Gates se materializó como un paisaje de color y formas que se multiplicaron con el movimiento de los peatones, andando y dejando sus huellas, sobre las huellas del paisaje. Siete mil quinientos marcos de casi cinco metros de altura y un ancho variable de entre 1,80 y 5,50 metros fueron instalados siguiendo los senderos de un parque de 342 hectáreas. La imagen aérea, posible desde las decenas de rascacielos que contienen el sitio, se desplegó como una sucesión de pinceladas continuas, de curvas y contra curvas, cuyo color azafrán se definía en contraste al plano oscuro del suelo y las copas peladas de los árboles.

La experiencia peatonal, establecida como objetivo primordial y hecho definitorio de este paisaje temporáneo, se fundó en la interacción entre naturaleza, arte y conducta humana. Las telas translúcidas de color azafrán flotando sobre las cabezas de los caminantes otorgaron brillos dinámicos y tonos cambiantes, los cuales respondían a todas las posibles luces del día, matinales, tardías, diáfanas o brumosas, que además variaban a través de los días; percibidas anaranjadas, rojizas y doradas, las superficies ondulantes respondían además a los caprichos del viento y de las condiciones climáticas locales, diariamente.

Con un telón de fondo, o más bien un escenario-marco de 360 grados, compuesto de edificios característicos de la ciudad de New York, esta puesta escenográfica urbana (o paisaje efímero que rescata un paisaje establecido) detiene mentalmente por un momento a quien la recorre, lo enfrenta con lo permanente o supuestamente permanente y, por sobre todas las cosas, le permite encontrar puntos de encuentro entre lo real y lo ficticio.

Puntos de encuentro entre lo teatral, lo real, lo urbano, lo natural.

\section{Arquitectura(s)}

La aparente pérdida de confines y límites, la disolución de los bordes, la preeminencia de la mirada difusa y móvil, la estructuración geométrica menos evidente, rígida, previsible... Todo ello son características típicas del paisaje que enriquecen la identidad de la arquitectura. (Daniela Colafranceschi, Landscape +100 palabras para habitarlo)

Dentro de las obras más impresionantes y emblemáticas de la arquitectura moderna se encuentra la Sagrada Familia de Antoni Gaudí, en Barcelona. Obra comenzada en 1884 y aún inconclusa, representa quizás el ejemplo de diseño arquitectónico más increíble inspirado en formas de la naturaleza. 
La imagen más representativa de esta iglesia es la de su conjunto: una forma que se desarrolla vegetalmente modelando torres y pináculos que parecen emerger de una gran base de roca; la misma remite directamente al paisaje en el cual Gaudí basó su diseño: las montañas de Montserrat ubicadas unos $50 \mathrm{Km}$. al noroeste de Barcelona.

La otra imagen característica, es la de los detalles escultóricos en cada uno de los portales que se desarrollan en la fachada, dentro de los cuerpos de las torres, y que manifiestan una organicidad tal sólo comparable a aquella de la naturaleza; la misma piel de la construcción, conformada con ladrillos, asemeja formas animales y vegetales superpuestas e integradas: escamas, columnas vertebrales, troncos y hojas conforman la principal superficie de la construcción.

Para el diseño de las columnas, Gaudí se inspiró directamente en la imagen del tronco de los eucaliptos, tomándolos no solo como referencia estética sino también como ejemplo de estructura resistente. Explicando en una oportunidad, a quienes visitaban su taller, en cuáles elementos había encontrado el ideal para sus diseños, declaró: "Un árbol en pie sostiene sus ramas, éstos sus tallos y éstos las hojas. Cada parte aislada crece en armonía, sublime desde que el artista Dios la concibió".

Las formas curvas y las líneas orgánicas típicas del movimiento modernista catalán, manifestación del Art Noveau en España, lograban en la obra de Gaudí una expresión máxima a través del modelado de las superficies, como si estas no fueran planos sino masas plásticas. El estudio de los sistemas de fuerzas de los materiales respaldó técnicamente sus creaciones, pero lo que las eleva a un nivel extraordinario de diseño es la inmensa riqueza de formas y sus combinaciones de carácter casi fantástico; en la Sagrada Familia, la correspondencia visual con el paisaje local deja establecida la clara relación entre arquitectura y naturaleza que este artista genial percibía, exploraba y se encargaba de demostrar.

\section{Ciudad(es)}

El Atlas tiene esa virtud: revela la forma de las ciudades que todavía no poseen forma ni nombre. Está la ciudad con la forma de Amsterdam, semicírculo que mira hacia el septentrión, con canales concéntricos: de los Príncipes, del Emperador, de los Señores; está la ciudad con la forma de York, encajonada entre altos brezales, amurallada, erizada de torres; está la ciudad con la forma de Nueva Amsterdam, llamada también Nueva York, atestada de torres de cristal y acero sobre una isla oblonga entre dos ríos, con calles como profundos canales todos rectilíneos salvo Broadway.

El catálogo de las formas es interminable, mientras cada forma no haya encontrado su ciudad, nuevas ciudades seguirán naciendo. Donde las formas agotan sus variaciones y se deshacen, comienza el fin de las ciudades. En los últimos mapas del atlas se diluían retículas sin principio ni fin, ciudades con la forma de Los Ángeles, con la forma de Kyoto-Osaka, sin forma. (Italo Calvino, Las Ciudades Invisibles)

Las ciudades son expansivas, temporarias -aunque con ansias de ser permanentes- rebeldes, frágiles, fractales, extrañas para el foráneo, cotidianas para el local; crecen hacia los bordes, en los bordes, bordeando ríos y canales, creando más bordes, de adentro hacia afuera y viceversa; refugian, expulsan, reciben, delatan, despiden, mantienen y retienen a su gente; suenan, huelen, ven y son vistas, se visten de gala y también de luto, velan, son veladas, renacen, se rehacen, reconstruyen y diluyen, aunque poco; se inundan, se mueven, tiemblan, se reducen, aumentan en altura y en anchos variables, deformes, amorfos, a veces geométricos pero sobre todo orgánicos, anchos orgánicos que se 
modifican cada día, cada hora, cada minuto. Son el hombre y la naturaleza, ¿qué más terrible, más fascinante, más imposible y más necesario que la relación entre hombre y naturaleza? ¿Y que reflejo más evidente de sus conexiones y desconexiones que la ciudad y sus deseos?

La ciudad se apoya sobre el paisaje existente, se alimenta del mismo, lo invade y lo modifica; la ciudad es paisaje. Paisaje modificado, convertido en otro paisaje.

La ciudad, por otro lado, se condiciona con el paisaje existente y se modela de acuerdo al mismo; la ciudad es paisaje convertido en ciudad.

Las ciudades capitales de Latinoamérica, con excepción de Buenos Aires, todas se desarrollan entre cerros y montañas, que las cruzan, que las bordean o que las vigilan; sus laderas se convierten en redes vivas de construcciones y calles y gentes que devoran la naturaleza y, solo en algunos casos, son detenidas por ella.

Medellín, por ejemplo, es un ejemplo de ciudad-organismo vivo. Con una historia de violencia cíclica y aparentemente, al menos por un largo tiempo, desenfrenada, esta ciudad se materializa hoy como lugar de cambio, crecimiento y posibilidades. Es en sus laderas, las de los cerros que enmarcan el valle habitado, en donde en el presente se intentan arquitecturas nuevas, sociales e inclusivas y, complementariamente, en donde se practican metodologías de urbanidad que nunca antes se habían imaginado siquiera. Bordes de quebradas rediseñados, puentes que conectan barrios y un metrocable que mueve a la gente desde abajo hacia arriba y desde arriba hacia abajo sin distinción, son algunas de esas prácticas. Lo no-planificado, o la necesidad de los que no pudieron acceder a ser recibidos por la ciudad, se convierte en el arma de destrucción de la topografía que enmarca y condiciona a esa ciudad. Es casi como si ésta última aceptara las "geo-condiciones" impuestas por la orografía existente, sus límites y dificultades, pero se derramara luego de a poco sobre ella, sin miramientos ni respetos ni piedades. El proceso de modificación se va desarrollando lento; el paisaje busca volver a ser reflejado, reconstruido o, mínimamente, imaginado, pero es a través de la imaginación que primero se establecen los lugares. Ciudades invisibles que buscan tener una forma, nacida de unos paisajes, que quieren ser ciudades, visibles.

\section{Antropología(s)}

Cráteres, desiertos salados, acantilados, montañas cortadas: todos los paisajes que nos sugieren el fin del mundo también nos sugieren su comienzo. Quizá, en realidad, ambos acontecimientos sean uno solo y corresponda a nuestra capacidad de ficción la tarea de mantenerlos férreamente separados para inventar el tiempo, la historia y, en la más sofisticada pirueta de la fantasía, inventarnos a nosotros mismos. (Rafael Argullol, El cazador de instantes: cuadernos de travesía)

El Salar de Uyuni, en Bolivia, es la concentración más grande de sal del planeta. Se extiende como una superficie de 12.000 kilómetros cuadrados creando un manto místicamente blanco en medio de un paisaje de desierto. Desde un avión, el paisaje se percibe como una visión óptica, o más bien una confusión óptica: el observador primero piensa y entiende el blanco como nieve y luego se cuestiona, se auto-rectifica, porque el resto del desierto se verifica diferente. El salar es solamente una gran mancha en la inmensidad de la arena.

Durante los meses de clima seco el plano del suelo se conforma de costras de sal delimitadas por las grietas que se abren naturalmente en el mismo; el paisaje es lunar. En época de lluvias el manto se 
materializa como una fina capa de agua que se convierte en un inmenso espejo del cielo, generalmente brumoso y surcado de nubes; el paisaje es reflejo de sí mismo, el blanco se refleja en el blanco, el horizonte se pierde. Y con él se pierde también toda referencia de distancia y de cercanía.

Sin embargo, ni el misticismo ni el surrealismo ni la eternidad de este paisaje eliminan la posibilidad de la presencia del hombre; al contrario, parecieran atraerlo, imantarlo hacia sus confines en principio imaginados.

Dos visiones son las que comprueban esta presencia. La primera, interrumpiendo la vasta superficie horizontal: los camiones que recogen la sal y los montículos de forma cónica en donde ésta se va acumulando como resultado de horas de paleo; la segunda, algo menos ficticia: los precarios asentamientos que se levantan en sus bordes, en donde familias locales se ocupan del proceso de filtrado de la sal. Luego de empaquetada, la misma será transportarla a lo largo de caminos remotos y finalmente comercializada en las ciudades. Es la sal de cada día.

El hombre explora, conquista, cultiva la tierra, doma a las fieras, se provee a sí mismo, inventa, escala montañas, surca los mares, sobrevuela la Tierra, pisa la Luna, es centro del universo pero sin el universo no sobrevive; se excede, aprende, se replantea y finalmente se re-humaniza.

El acto humano es huella en el paisaje, signo y significado para el acto humano siguiente.

\section{Historia(s)}

Toda estadística, toda labor meramente descriptiva o informativa, presupone la espléndida y acaso insensata esperanza de que en el vasto porvenir, hombres como nosotros, pero más lúcidos, inferirán de los datos que les dejamos alguna conclusión provechosa o alguna generalización admirable. (Jorge Luis Borges y Adolfo Bioy Casares, Una tarde con Ramón Bonavena en Crónicas de Bustos Domecq)

En Las nueve leyes de Dios, Kevin Kelly habla de "cambiar el cambio". Básicamente, explica a la evolución como la aceptación del cambio a través del tiempo y, en un nivel más complejo, agrega que una evolución profunda es la aceptación del "cambio de las leyes que producen cambios" a través del tiempo. Las leyes del cambio son auto-cambiantes; no hay, en cualquier caso, manera de predecir a las mismas o de garantizar su inamovilidad o permanencia.

Estas son las leyes de la naturaleza pero también las leyes de los hombres, a nivel personal y de la sociedad que conforma. Son, de igual forma, las leyes de modificación, construcción y destrucción del paisaje en que nos movemos. Adaptarse a ellas, tanto como ser autores de su redefinición, puede otorgar la flexibilidad necesaria para responder correctamente a las necesidades que van surgiendo de manera diversa a través del tiempo.

Los hechos del pasado alimentan, justifican y condicionan la posibilidad de brindar respuestas acertadas en el presente. El movimiento debe ser sincrónico.

El sincronismo del proceso de cambio de los paisajes con el desarrollo de la historia del hombre no es siquiera una necesidad o una condición de supervivencia de los mismos; es un dato imprescindible para escribir esa historia. A su vez, las leyes internas de la historia -el sincronismo del paso del tiempo con los hechos, las respuestas y los cambios del hombre- son cambiantes e impredecibles.

La evolución del paisaje es, entonces, quizás tan solo una ilusión. Una manera de querer adelantarse a los posibles futuros hechos que nos tiene guardados, misteriosamente, la historia. 


\section{Reflexiones (concretas)}

- El paisaje es, al igual que el hombre y que la ciudad, un organismo vivo y, como tal, un sistema. No cabe duda de que el hombre es un organismo vivo, por supuesto, como ser biológico; la ciudad, por otro lado, es también un sistema que crece, evoluciona, se reproduce, muere, renace.

Y sistema es también el paisaje, con sus ciclos, naturales y antrópicos; la ciudad, de hecho, es paisaje. El hombre lo es.

Hay un continuo infinito entre estos componentes. El paisaje es donde el continuo se refleja, y es también el continuo mismo. Los límites se superponen; las palabras, en su terco afán de definir, pierden todo sentido.

Lo que queda, en todo caso, es la existencia de las partes que conforman un todo, y la relación entre ellas, dinámica y fluyente.

Vida: Entropía.

- La vuelta a algunas raíces, a un paisaje primigenio o primitivo, se identifica necesaria y evidente desde todas las miradas expuestas.

El modelo de vinculación con el territorio de los pueblos antiguos, algunos de los cuales hoy subsisten o subsisten sus creencias y rituales de maneras diferentes, junto a ciertas prácticas actuales que los imitan y emulan, pareciera ser una posibilidad de mejor manejo y comprensión del entorno. Entorno entendido no como una mera estructura, física, social o filosófica, sino como un todo, cuyo consecuente valor es mítico y, probablemente, redentor.

No es necesaria la involución ni es necesario un pensamiento innecesariamente ortodoxo o uno que no propicie el cambio, pero sí se verifica una necesidad de vinculación más prístina con los lugares en los que habitamos y su naturaleza. Una vinculación que nos permita descansar en el futuro.

- Como hombres que somos - principales modificadores del paisaje- necesitamos, de vez en cuando, observar con perspectiva. Así, al desplazarnos de la histórica posición de "centro del universo" que caracteriza la cosmovisión occidental, podremos entender que somos solamente unas manchas en el paisaje, al cual, sin embargo, nuestro accionar no le es indiferente.

Es, en todo caso, una cuestión de tiempo; más tarde o más temprano, nuestras acciones definen resultados.

El paisaje que apreciamos desde la ventana de un avión no es otro que el reflejo de nuestro paso por la tierra a través del tiempo. Un espejo de nuestros procesos y las huellas que los delatan y, algunas veces, los justifican. Es lo que fuimos y lo que podremos ser.

¿Será por eso que resulta imposible no desear mirar hacia abajo desde un avión?

La posición de perspectiva y la investidura de testigo externo nos permiten perder escala, sabernos ínfimos, dependientes y prescindibles. Nos permite comprender el paisaje como presencia omnipresente y eterna, y sin embargo vulnerable.

Percibir las huellas que dejamos sobre la tierra y las marcas que nos conducen a otros lugares es una manera de restablecer lazos reales con el continuo espacial del que somos parte. Sea cual fuera la manera en que el paisaje es comprendido, la vinculación con el mismo - distante o cercana - se eleva como una necesidad primaria; un deseo primitivo que permanece, bajo formas diversas, en el tiempo. Probablemente, la más obvia respuesta a un presente global (¿lógicamente?) caótico. 


\section{Bibliografía}

Borges, Jorge Luis y Bioy Casares, Adolfo. (1963). Crónicas de Bustos Domecq. Buenos Aires: Editorial Losada, SA

Calvino, Italo. (1998). Las Ciudades Invisibles. Madrid: Ediciones Siruela.

Colafranceschi, Daniela. (2007). Landscape + 100 palabras para habitarlo. Barcelona: Editorial Gustavo Gili

Christo and Jeanne-Claude. (2005). The Gates, Central Park, New York 1979-2005. Koln: Editorial Taschen

Galofaro, Luca. (2003). Artscapes: el arte como aproximación al paisaje contemporáneo. Barcelona: Editorial Gustavo Gili

Kelly, Kevin. (2002). Las nueve leyes de Dios. Revista Oeste \# 15, Revista de arquitectura, urbanismo, arte y pensamiento contemporáneo II Época. Colegio Arquitectos de Extremadura

Rosell, Quim. (2001). Rehacer paisajes, Después de Afterwards. Barcelona: Editorial Gustavo Gili,

The Diary of Frida Kahlo, an intimate portrait. (2001). New York: Harry Abrams, Inc y México: La Vaca Independiente SA Zerbst, Rainer. (1989). Antoni Gaudi. Koln: Editorial Taschen.

Real Academia Española

Summary: Many of the most emblematic and significant present disciplines of design, as much as others whose center is human being -its needs and its behaviours- own a deeply necessary and defined bow with landscape. Those disciplines are fed and are inspired by landscape; they talk about it while referring to it; they are originated in it and they conform it at the same time they transform it. Which is that bow and how it is exactly defined? To what refer concepts like landscapearchitecture, landscape-city, landscape-body, landscape-theater, landscape-time and landscape-rite? This text looks for to inspire each one of the authors to reveal a little more about the essence of this wonderful bow by providing ideas, concepts and examples.

Key words: Landscape - architecture - clothing - body - stage scene - theater - city-furniture - history-time - anthropology - rite

Resumo: Muitas das mais emblemáticas e significativas disciplinas de design atuais, tanto como outras cujo centro é o homem -suas necessidades e seus comportamentos- possuem um laço necessário e definido com a paisagem. Alimentamse e inspiram-se nele, referem-se a ele e são referentes do mesmo, originam-se nele e ao mesmo tempo o conformam e o transformam. ¿Qual é esse laço e como se define exatamente? A que nos remetem as duplas paisagem-arquitetura, paisagem-cidade, paisagem-corpo, paisagem-teatro, paisagem-tempo e paisagem-rito? Este texto-disparador procura inspirar a cada um dos autores para que, com suas idéias, conceitos e exemplos, deixem ao descoberto algo mais da essência daquele maravilhoso laço.

Palavras chave: paisagem - arquitetura - indumentária - corpo - cenografia - teatro - cidade - mobiliário urbano - história -tempo - antropologia - rito

\footnotetext{
* Arquitecta (UB) con posgrados en Especialización de Planificación del Paisaje (UBA) y en Ambiente, Sociedad y Economía (FLACSO). Trabaja en la curadoría y difusión de proyectos latinoamericanos de arquitectura del paisaje y planificación para la Landscape Architecture Magazine (USA), Landscape Design China (China), Topos Global (Alemania), Arquine (México), Landscape Magazine (United Arabs Emirates), Barzon (Argentina) y colabora con Architectural Record (USA), Supersudaca y La Nación. Es autora del libro Latinscapes, el paisaje como materia prima, de la serie Land\&Scapes, Editorial Gustavo Gili (España, 2008). Es docente de la Universidad Di Tella y ha brindado charlas y seminarios del tema en la Universidad
} 
Nacional de Buenos Aires, Universidad de Palermo, Universidad Católica de Córdoba, Universidad de La Plata, Universidad Los Andes (Bogotá) y en la Sociedad Central de Arquitectos (Bs. As). Visita cada uno de los proyectos sobre los que escribe y trabaja con fotógrafos profesionales de Bogotá, Medellín, Santiago, São Paulo, Belém, Caracas y Buenos Aires. 